\title{
RNA Analysis
}

National Cancer Institute

\section{Source}

National Cancer Institute. RNA Analysis. NCI Thesaurus. Code C18473.

Molecular biology procedures, including Northern Blot, Differential display, RT-PCR, and RNase protection for qualifying or quantifying RNA. (NCl/OSP) 